\title{
Iron(II)-Catalyzed Heck-Type Coupling of Vinylarenes with Alkyl lodides
}

\author{
Haigen Xiong, ${ }^{\dagger, \dagger}$ Yajun Li, ${ }^{\dagger}$ Bo Qian, ${ }^{\dagger}$ Rongbiao Wei, ${ }^{\dagger}$ Erik V. Van der Eycken, ${ }^{*},{ }^{\S}, \|_{\odot}$ \\ and Hongli $\mathrm{Bao}^{*},+,+$ (i)
}

${ }^{\dagger}$ Key Laboratory of Coal to Ethylene Glycol and Its Related Technology, State Key Laboratory of Structural Chemistry, Center for Excellence in Molecular Synthesis, Fujian Institute of Research on the Structure of Matter, Chinese Academy of Sciences, 155 Yangqiao Road West, Fuzhou, Fujian 350002, P. R. of China

\#University of Chinese Academy of Sciences, Beijing, 100049, P. R. of China

${ }^{\S}$ Laboratory for Organic \& Microwave-Assisted Chemistry (LOMAC), Department of Chemistry, University of Leuven (KU Leuven), Celestijnenlaan 200F, Leuven, Belgium

"Peoples' Friendship University of Russia (RUDN University), Miklukho-Maklaya Street 6, Moscow 117198, Russia

\section{Supporting Information}

ABSTRACT: An iron(II)-catalyzed radical alkyl Heck-type reaction of alkyl iodides with vinylarenes under mild conditions has been reported. $t$-Butyl peroxybenzoate (TBPB) behaves simultaneously as a radical relay initiator, a precursor for the generation of alkyl radical from alkyl iodides, and an oxidant to recycle iron(II)/iron(III). Unactivated primary, secondary, and tertiary alkyl iodides are compatible with the reaction conditions. The mechanistic studies suggest that a radical-polar-crossover pathway might be involved in the catalytic cycle.

$\mathrm{T}$ he Mizoroki-Heck coupling reaction has been confirmed as one of the most significant methods for the construction of carbon-carbon bond in organic synthesis since 1970s. ${ }^{1}$ However, compared to the rapid development of coupling of aryl or vinyl halides with alkenes, ${ }^{2}$ the coupling of olefins and alkyl halides bearing $\beta$-hydrogen(s) has rarely been documented. $^{3}$ The reason is that the alkyl-metal species is inclined to undergo $\beta$-hydride elimination before insertion of alkene. ${ }^{4}$ Additionally, the rate of oxidative addition of alkyl halide to metal-center is slower than that of aryl halide. ${ }^{5}$ To overcome the issues mentioned above, radical strategies for alkyl Heck (or Heck-type) reaction have been established. ${ }^{6}$ Exploratory studies on radical Heck-type reaction with activated alkyl halides have been reported by Lei, Nishikata, and Thomas, in the presence of nickel salt, ${ }^{7}$ ruthenium salt, ${ }^{8}$ copper salt, ${ }^{9}$ and iron salt ${ }^{10}$ as the catalyst, respectively. The generated alkyl radicals are stabilized by the linked electronwithdrawing groups through conjugative effect, thus limiting the substrate scopes. Radical Heck-type reactions of unactivated alkyl halides have been pioneeringly achieved by Oshima with a ligated cobalt catalyst (Scheme 1a). ${ }^{11}$ However, a stoichiometric amount of trimethylsilylmethylmagnesium chloride is crucial to smoothly promote the reaction. In recent years, palladium salts were found to be good catalysts for radical alkyl Heck-type reaction through an open-shell pathway. ${ }^{12,13} \mathrm{Fu}^{14}$ and Gevorgyan ${ }^{15}$ independently described elegant palladium-catalyzed Heck reactions of unactivated alkyl halides under photoirradiation (Scheme 1a). A range of alkyl halides, especially tertiary alkyl halides bearing $\beta$-hydrogen $(\mathrm{s})$,
Scheme 1. Intermolecular Alkyl Heck-type Reaction

$$
\begin{aligned}
& \text { a) Metal-catalyzed alkyl Heck-type reaction with/without light irradiation }
\end{aligned}
$$

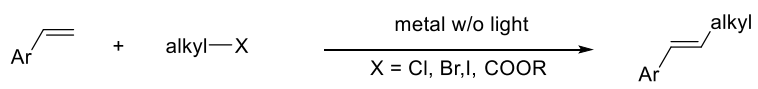

$$
\begin{aligned}
& \text { b) Acid-catalyzed alkyl Heck-type reaction }
\end{aligned}
$$

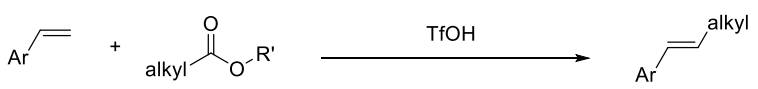

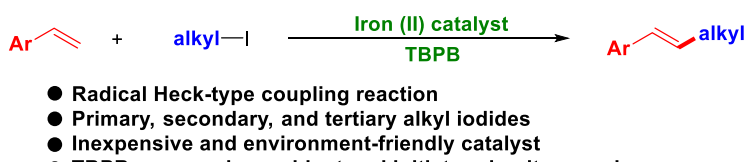

can be involved. However, these reactions need to proceed under light irradiation and to use noble metal as the catalyst.

Our group previously described a radical decarboxylative alkyl Heck-type reaction catalyzed by triflic acid (Scheme 1b) and iron catalysts. ${ }^{16,17}$ We found that $t$-butyl peroxybenzoate (TBPB) is a good initiator for the iron-catalyzed alkyl Hecktype reactions through a radical relay process. ${ }^{18,19}$ Considering that iron is an inexpensive and environmentally benign catalyst, $^{20}$ we reported herein a general iron-catalyzed radical alkyl Heck-type reactions with both unactivated and activated alkyl iodides (Scheme 1c). ${ }^{10}$

Received: December 17, 2018 
Initially, 4-tert-butylstyrene (1a) and alkyl iodide (2a) were used as the model substrates to explore the alkyl Heck-type reaction (Table 1). $5 \mathrm{~mol} \%$ of metal catalysts, such as

Table 1. Optimization of the Reaction Conditions ${ }^{a}$

\begin{tabular}{|c|c|c|c|c|}
\hline & $+\quad$ & $\begin{array}{r}\text { Metal cat } \\
\text { TBPB }(3 \mathrm{e}\end{array}$ & & aa \\
\hline entry & catalyst ( $\mathrm{mol} \%)$ & solvent & temp $\left({ }^{\circ} \mathrm{C}\right)$ & yield $(\%)^{b}$ \\
\hline 1 & $\mathrm{Pd}(\mathrm{OAc})_{2}(5)$ & THF & 50 & trace \\
\hline 2 & $\mathrm{NiCl}_{2}$ (5) & THF & 50 & trace \\
\hline 3 & $\mathrm{CuI}(5)$ & THF & 50 & trace \\
\hline 4 & $\mathrm{Fe}(\mathrm{OAc})_{2}$ & THF & 50 & trace \\
\hline 5 & $\mathrm{Fe}(\mathrm{OTs})_{3}$ & THF & 50 & 25 \\
\hline 6 & $\mathrm{Fe}(\mathrm{OTf})_{3}(5)$ & THF & 50 & 66 \\
\hline 7 & $\mathrm{Fe}(\mathrm{OTf})_{2}(5)$ & THF & 50 & 70 \\
\hline 8 & $\mathrm{Fe}(\mathrm{OTf})_{2}(5)$ & $\mathrm{CH}_{3} \mathrm{CN}$ & 50 & 9 \\
\hline 9 & $\mathrm{Fe}(\mathrm{OTf})_{2}(5)$ & DME & 50 & 65 \\
\hline 10 & $\mathrm{Fe}(\mathrm{OTf})_{2}(5)$ & 1,4-dioxane & 50 & $73(72)^{c}$ \\
\hline 11 & $\mathrm{Fe}(\mathrm{OTf})_{2}(5)$ & 1,4-dioxane & 25 & trace \\
\hline 12 & $\mathrm{Fe}(\mathrm{OTf})_{2}(5)$ & 1,4-dioxane & 70 & 73 \\
\hline
\end{tabular}

${ }^{a}$ Reaction conditions: alkene $1 \mathrm{a}$ ( $1 \mathrm{mmol}, 1$ equiv), alkyl iodide $\mathbf{2 a}$ (3 mmol, 3 equiv), TBPB ( 3 mmol, 3 equiv), solvent $(4 \mathrm{~mL}), 3$ h. ${ }^{b}$ Yield of product was determined by crude. ${ }^{1} \mathrm{H}$ NMR. ${ }^{c}$ Isolated yield in parentheses.

$\mathrm{Pd}(\mathrm{OAc})_{2}, \mathrm{NiCl}_{2}, \mathrm{CuI}$, and $\mathrm{Fe}(\mathrm{OAc})_{2}$, were employed to run the reaction. Unfortunately, only a trace amount of alkylated product was detected in these cases when the reaction was performed at $50{ }^{\circ} \mathrm{C}$ in $\mathrm{THF}$ for $3 \mathrm{~h}$ (Entries 1-4). To our delight, $25 \%$ yield of the coupling product (3aa) was obtained by using $\mathrm{Fe}(\mathrm{OTs})_{3}$ as the catalyst (Entry 5). Inspired by this result, other iron catalysts were tested. While catalyst $\mathrm{Fe}(\mathrm{OTf})_{3}$ afforded product 3 aa in $66 \%$ yield, $\mathrm{Fe}(\mathrm{OTf})_{2}$ offered a better yield, as high as $70 \%$ (Entries 6 and 7 ). Then, the solvents were screened, and up to $72 \%$ isolated yield of 3 aa could be produced in 1,4-dioxane (Entry 10 vs Entries 8 and 9). When the reaction was performed at a lower temperature $\left(25^{\circ} \mathrm{C}\right)$, only a trace amount of product was detected (Entry 11). A higher temperature could not increase the yield of product (Entry 12).

With the optimal reaction conditions in hand, the scope of alkyl iodides was investigated (Scheme 2). Both of the acyclic and cyclic secondary alkyl iodides smoothly couple with 4-tertbutylstyrene (1a) to deliver the corresponding products (3ab$3 a e)$ in $51-71 \%$ yields. Tertiary alkyl iodide is transformed into product (3af) in $61 \%$ yield. A variety of primary alkyl coupling products (3ag-3aj), possessing long-chain alkyl, phenyl, chloride, and trifluoromethyl groups, are obtained in $39-50 \%$ yields. Perfluoroalkyl iodides are also compatible with this Heck-type reaction, affording the desired products (3ak$3 \mathrm{am})$ in moderate to good yields $(66-76 \%)$. In addition, 1chloro-2-iodo-tetrafluoroethane is used as a coupling partner, providing the product ( $3 \mathrm{an}$ ) in $86 \%$ yield. 2-Iodo-heptafluoropropane is applicable to the reaction, giving $81 \%$ yield of product 3ao. Difluoroacetylated alkene 3ap could be attained through this transformation in $58 \%$ yield. However, 3iodooxetane or tert-butyl 3-iodoazetidine-1-carboxylate fails to afford the corresponding product.

The alkyl Heck-type cross coupling reaction can also be extended to various styrene derivatives (Scheme 3 ). Styrene $\mathbf{1 b}$
Scheme 2. Scope of Alkyl Iodides ${ }^{a}$
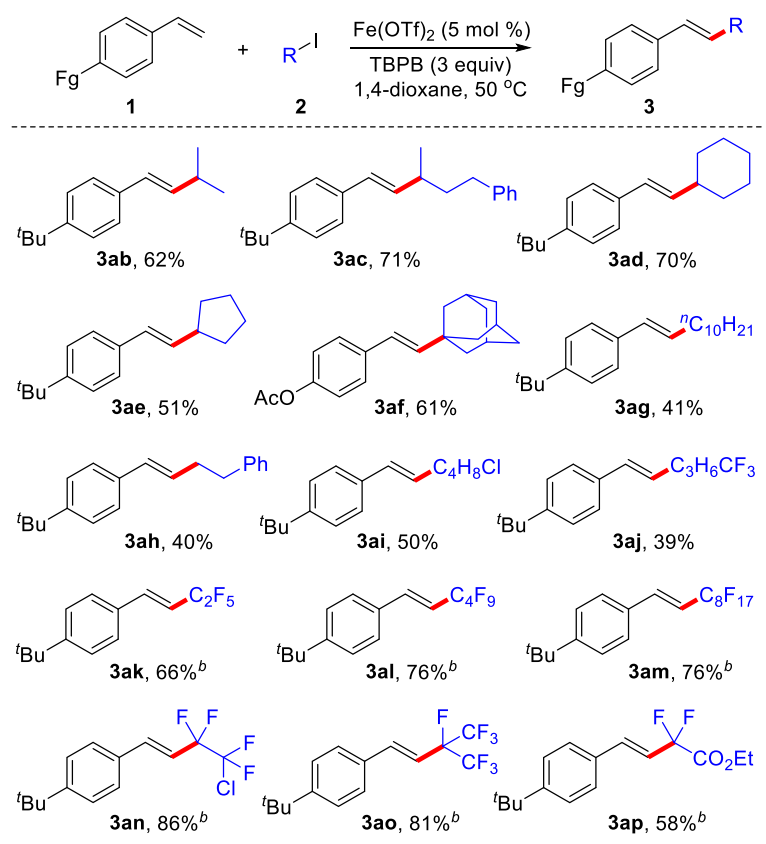

${ }^{a}$ Reaction conditions: alkene ( $1 \mathrm{mmol}, 1$ equiv), alkyl iodide 2 ( 3 mmol, 3 equiv), $\mathrm{Fe}(\mathrm{OTf})_{2}$ (5 mol \%), TBPB ( 3 mmol, 3 equiv), 1,4dioxane $(4 \mathrm{~mL}), 50{ }^{\circ} \mathrm{C}, 3 \mathrm{~h}$. Isolated yields. ${ }^{b}$ Alkene ( $1 \mathrm{mmol}, 1$ equiv), alkyl iodide 2 ( $2 \mathrm{mmol}, 2$ equiv), TBPB ( $2 \mathrm{mmol}, 2$ equiv), DME (4 mL), $2 \mathrm{~h}$

Scheme 3. Scope of Aryl Olefins ${ }^{a}$

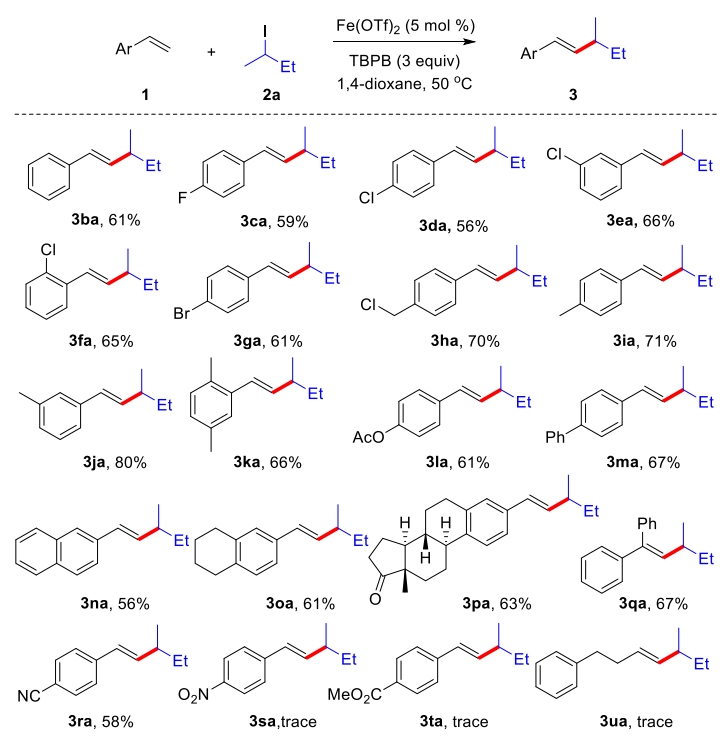

${ }^{a}$ Reaction conditions: alkene $\mathbf{1}$ ( $1 \mathrm{mmol}, 1$ equiv), alkyl iodide $\mathbf{2 a}$ ( 3 mmol, 3 equiv), $\mathrm{Fe}(\mathrm{OTf})_{2}$ ( $\left.5 \mathrm{~mol} \%\right)$, TBPB ( $3 \mathrm{mmol}, 3$ equiv), 1,4dioxane $(4 \mathrm{~mL}), 50{ }^{\circ} \mathrm{C}, 3 \mathrm{~h}$. Isolated yields.

is employed to react with alkyl iodide $2 \mathbf{a}$, leading to the generation of product $3 \mathbf{b a}$ in $61 \%$ yield. The aryl alkenes bearing electron-withdrawing (halides) and electron-donating groups $(3 \mathrm{ca}-3 \mathrm{ma})$ are tolerated in the reaction with moderate to good efficiency (56-80\%). 2-Vinyl naphthalene and 6-vinyl tetrahydronaphthalene afford the alkyl-Heck products (3na and $3 \mathrm{ma}$ ) in $56 \%$ and $61 \%$ yields, respectively. Particularly, the estrone derivative containing a $\mathrm{C}=\mathrm{C}$ double bond is readily converted into the corresponding product (3pa, 63\% yield). 
1,1-Disubstitued alkene is also compatible to the reaction, giving the alkylated alkene (3qa) in 67\% yield. Notably, 4vinylbenzonitrile could afford the desired product (3ra) in 58\% yield, while methyl 4-vinylbenzoate and 1-nitro-4-vinylbenzene are incompatible with the optimized reaction conditions. Moreover, but-3-en-1-ylbenzene as an aliphatic alkene, and benzyl acrylate or pent-1-en-3-one as a conjugated alkene, are also not tolerated the reaction conditions and fail to afford the desired products.

To insight into the mechanism of this alkyl Heck-type cross coupling reaction, the preliminary experiments were performed (Scheme 4). The control experiments proceeded separately in

\section{Scheme 4. Preliminary Mechanistic Studies}

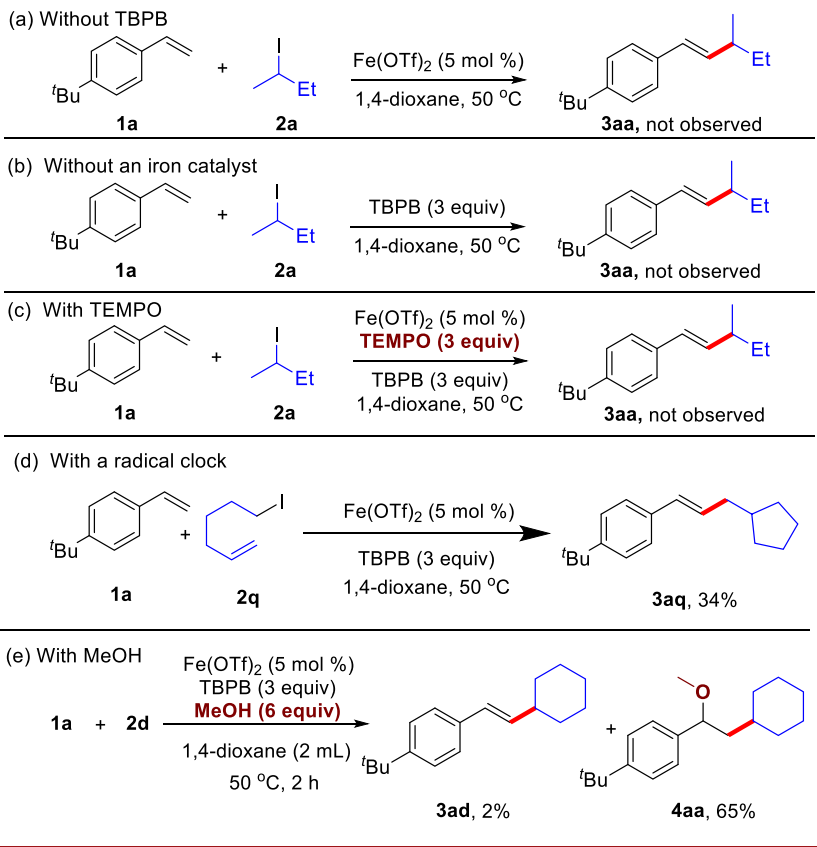

the absence of TBPB or $\mathrm{Fe}(\mathrm{OTf})_{2}$ under standard reaction conditions, and alkylated product (3aa) is not detected by GCMS in both cases (Scheme 4a,b). These results indicated that both the iron catalyst and the TBPB are crucial for this alkyl Heck-type transformation. Moreover, when 3 equiv of 2,2,6,6tetramethyl-1-piperidinyloxy (TEMPO) is added as a radical inhibitor, the product (3aa) cannot be observed as well (Scheme 4c). Moreover, substrate 6-iodohex-1-ene (2q) could only afford a cyclized Heck-type product (3aq) (Scheme 4d). These results imply that radical species might be involved in the reaction. With methanol as an additive, the selective formation of product 4 aa suggested that a benzylic cation might be involved (Scheme 4e).

Therefore, based on the mechanistic experiments, a possible mechanism for the alkyl Heck-type reaction is proposed (Scheme 5). Fe(II) is oxidized by TBPB, generating Fe(III) and a tert-butoxy radical (I), followed by the production of a methyl radical (II) and acetone. The alkyl radical (III) would arise via atom transfer process between methyl radical (II) and alkyl iodide. The addition of the alkyl radical (III) to aryl alkene leads to the formation of a benzyl radical (IV) which could be further oxidized by the Fe(III) species, providing a benzyl cation and the regenerated $\mathrm{Fe}(\mathrm{II})$ species. As a consequence of deprotonation of the benzyl cation, the Heck-type product is acquired.
Scheme 5. Possible Mechanism

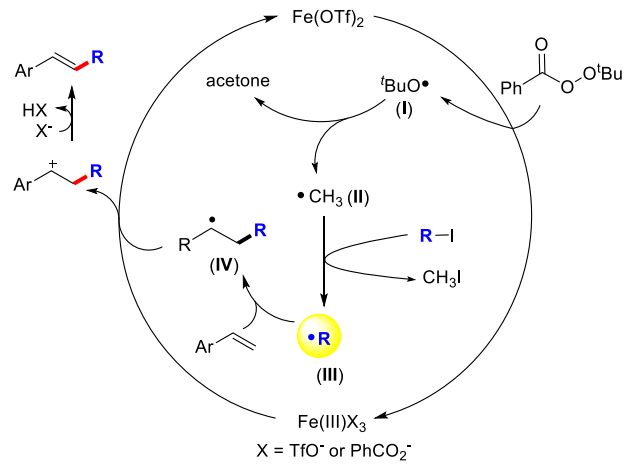

In summary, a radical relay process for iron(II)-catalyzed Heck-type alkylation of aryl alkenes with alkyl iodides has been established. Activated/unactivated primary, secondary, and tertiary alkyl iodides are compatible in this reaction to afford various alkyl alkenes in moderate to good yields. TBPB is employed as an internal oxidant to oxidize iron(II) species, meanwhile, as an initiator to promote the generation of alkyl radical from alkyl iodides. The mechanistic studies suggest that a radical-polar-crossover pathway might be involved in the catalytic cycle.

\section{ASSOCIATED CONTENT}

\section{S Supporting Information}

The Supporting Information is available free of charge on the ACS Publications website at DOI: 10.1021/acs.orglett.8b04024.

Experimental procedures, characterization of new compounds, synthetic applications, mechanistic studies, NMR spectra (PDF)

\section{AUTHOR INFORMATION}

\section{Corresponding Authors}

*E-mail: hlbao@fjirsm.ac.cn.

*E-mail: erik.vandereycken@chem.kuleuven.be.

\section{ORCID}

Yajun Li: 0000-0001-6690-2662

Erik V. Van der Eycken: 0000-0001-5172-7208

Hongli Bao: 0000-0003-1030-5089

Notes

The authors declare no competing financial interest.

\section{ACKNOWLEDGMENTS}

H.B. thanks the National Key R\&D Program of China (2017YFA0700103), the NSFC (Grant Nos 21502191, 21672213, and 21871258), the Strategic Priority Research Program of the Chinese Academy of Sciences (Grant No. XDB20000000), and the Haixi Institute of CAS (Grant No. CXZX-2017-P01) for financial support. E.V.dE. acknowledges the support of RUDN University Program 5-100.

\section{REFERENCES}

(1) (a) Mizoroki, T.; Mori, K.; Ozaki, A. Arylation of Olefin with Aryl Iodide Catalyzed by Palladium. Bull. Chem. Soc. Jpn. 1971, 44, 581-581. (b) Heck, R. F.; Nolley, J. P. Palladium-catalyzed vinylic hydrogen substitution reactions with aryl, benzyl, and styryl halides. $J$. 
Org. Chem. 1972, 37, 2320-2322. (c) The Mizoroki-Heck Reaction, Oestreich, M., Ed.; Wiley: Chichester, 2009.

(2) For selected reviews on Heck reactions: (a) Cabri, W.; Candiani, I. Recent Developments and New Perspectives in the Heck Reaction. Acc. Chem. Res. 1995, 28, 2-7. (b) Amatore, C.; Jutand, A. Anionic $\mathrm{Pd}(0)$ and $\mathrm{Pd}(\mathrm{II})$ Intermediates in Palladium-Catalyzed Heck and Cross-Coupling Reactions. Acc. Chem. Res. 2000, 33, 314-321. (c) Beletskaya, I. P.; Cheprakov, A. V. The Heck Reaction as a Sharpening Stone of Palladium Catalysis. Chem. Rev. 2000, 100, 3009-3066. (d) Dounay, A. B.; Overman, L. E. The asymmetric intramolecular Heck reaction in natural product total synthesis. Chem. Rev. 2003, 103, 2945-2964. (e) Ruan, J.; Xiao, J. From alphaarylation of olefins to acylation with aldehydes: a journey in regiocontrol of the Heck reaction. Acc. Chem. Res. 2011, 44, 614626. (f) Le Bras, J.; Muzart, J. Intermolecular dehydrogenative Heck reactions. Chem. Rev. 2011, 111, 1170-1214.

(3) (a) Mori, M.; Oda, I.; Ban, Y. Cyclization of $\alpha$-haloamide with internal double bond by use of the low-valent metal complex. Tetrahedron Lett. 1982, 23, 5315-5318. (b) Wu, G.-z.; Lamaty, F.; Negishi, E.-i. Metal-Promoted Cyclization. 26. Palladium-Catalyzed Cyclization of Benzyl Halides and Related Electrophiles Containing Alkenes and Alkynes as a Novel Route to Carbocycles. J. Org. Chem. 1989, 54, 2507-2508. (c) Yi, P.; Zhuangyu, Z.; Hongwen, H. Vinylation of Alkyl Halides Catalyzed by Palladium Catalyst. Synth. Commun. 1992, 22, 2019-2029. (d) Yi, P.; Zhuangyu, Z.; Hongwen, H. Vinylation of Benzylic Quaternary Ammonium Salts Catalyzed by Palladium. Synthesis 1995, 1995, 245-247. (e) Wang, L.; Pan, Y.; Jiang, X.; Hu, H. Palladium catalyzed reaction of $\alpha$-chloromethylnaphthalene with olefins. Tetrahedron Lett. 2000, 41, 725-727. (f) Higuchi, K.; Sawada, K.; Nambu, H.; Shogaki, T.; Kita, Y. A convenient synthesis of the beraprost intermediate: a useful method for introducing a C3 unit at the benzyl position. Org. Lett. 2003, 5, 3703-3704. (g) Glorius, F. Palladium-catalyzed Heck-type reaction of 2-chloro acetamides with olefins. Tetrahedron Lett. 2003, 44, 5751-5754. (h) Narahashi, H.; Yamamoto, A.; Shimizu, I. Heck-type Benzylation of Olefins with Benzyl Trifluoroacetates. Chem. Lett. 2004, 33, 348-349. (i) Firmansjah, L.; Fu, G. C. Intramolecular Heck reactions of unactivated alkyl halides. J. Am. Chem. Soc. 2007, 129, 11340-11341. (j) Surapanich, N.; Kuhakarn, C.; Pohmakotr, M.; Reutrakul, V. Palladium-Mediated Heck-Type Reactions of [(Bromodifluoromethyl)sulfonyl]benzene: Synthesis of $\alpha$-Alkenyland $\alpha$-Heteroaryl-Substituted $\alpha, \alpha$-Difluoromethyl Phenyl Sulfones. Eur. J. Org. Chem. 2012, 2012, 5943-5952.

(4) Bräse, S.; de Meijere, A. In Metal-Catalyzed Cross-Coupling Reactions, Diederich, F.; Stang, P. J., Eds.; Wiley: Weinheim, 1998; Chapter 3.

(5) Hartley, F. R.; Patai, S. The Chemistry of the Metal-Carbon Bond, 1985; Vol. 2.

(6) For selected reviews: (a) Tang, S.; Liu, K.; Liu, C.; Lei, A. Olefinic C-H functionalization through radical alkenylation. Chem. Soc. Rev. 2015, 44, 1070-1082. (b) Liu, Q.; Dong, X.; Li, J.; Xiao, J.; Dong, Y.; Liu, H. Recent Advances on Palladium Radical Involved Reactions. ACS Catal. 2015, 5, 6111-6137.

(7) Liu, C.; Tang, S.; Liu, D.; Yuan, J.; Zheng, L.; Meng, L.; Lei, A. Nickel-catalyzed Heck-type alkenylation of secondary and tertiary alpha-carbonyl alkyl bromides. Angew. Chem., Int. Ed. 2012, 51, 3638-3641.

(8) Liu, Q.; Yi, H.; Liu, J.; Yang, Y.; Zhang, X.; Zeng, Z.; Lei, A. Visible-light photocatalytic radical alkenylation of alpha-carbonyl alkyl bromides and benzyl bromides. Chem. - Eur. J. 2013, 19, 5120-5126.

(9) Nishikata, T.; Noda, Y.; Fujimoto, R.; Sakashita, T. An efficient generation of a functionalized tertiary-alkyl radical for coppercatalyzed tertiary-alkylative Mizoroki-Heck type reaction. J. Am. Chem. Soc. 2013, 135, 16372-16375.

(10) Zhu, K.; Dunne, J.; Shaver, M. P.; Thomas, S. P. Iron-Catalyzed Heck-Type Alkenylation of Functionalized Alkyl Bromides. ACS Catal. 2017, 7, 2353-2356.

(11) (a) Ikeda, Y.; Nakamura, T.; Yorimitsu, H.; Oshima, K. CobaltCatalyzed Heck-Type Reaction of Alkyl Halides with Styrenes. J. Am.
Chem. Soc. 2002, 124, 6514-6515. (b) Affo, W.; Ohmiya, H.; Fujioka, T.; Ikeda, Y.; Nakamura, T.; Yorimitsu, H.; Oshima, K.; Imamura, Y.; Mizuta, T.; Miyoshi, K. Cobalt-catalyzed trimethylsilylmethylmagnesium-promoted radical alkenylation of alkyl halides: a complement to the Heck reaction. J. Am. Chem. Soc. 2006, 128, 8068-8077 For a paper from Carreira group: . (c) Weiss, M. E.; Kreis, L. M.; Lauber, A.; Carreira, E. M. Cobalt-catalyzed coupling of alkyl iodides with alkenes: deprotonation of hydridocobalt enables turnover. Angew. Chem., Int. Ed. 2011, 50, 11125-11128. (d) Feng, Z.; Min, Q.-Q.; Zhao, H.-Y.; Gu, J.-W.; Zhang, X. A General Synthesis of Fluoroalkylated Alkenes by Palladium-Catalyzed Heck-Type Reaction of Fluoroalkyl Bromides. Angew. Chem., Int. Ed. 2015, 54, 1270-1274. (e) Wang, Z.-Y.; Wan, J.-H.; Wang, G.-Y.; Jin, R.-X.; Lan, Q.; Wang, X.-S. Nickel-Catalyzed Heck-Type Monofluoroacetation of Styrenes for Facile Synthesis of Allylic Fluorides. Chem. - Asian J. 2018, 13, 261-265. (f) Bao, Y.; Wang, G.-Y.; Zhang, Y.-X.; Bian, K.-J.; Wang, $\mathrm{X}$.-S. Copper-catalyzed formylation of alkenyl $\mathrm{C}-\mathrm{H}$ bonds using $\mathrm{BrCHCl}_{2}$ as a stoichiometric formylating reagent. Chem. Sci. 2018, 9, 2986-2990.

(12) (a) Kurandina, D.; Parasram, M.; Gevorgyan, V. Visible LightInduced Room-Temperature Heck Reaction of Functionalized Alkyl Halides with Vinyl Arenes/Heteroarenes. Angew. Chem., Int. Ed. 2017, 56, 14212-14216. (b) Bloome, K. S.; McMahen, R. L.; Alexanian, E. J. Palladium-catalyzed Heck-type reactions of alkyl iodides. J. Am. Chem. Soc. 2011, 133, 20146-20148. (c) Firmansjah, L.; Fu, G. C. Intramolecular Heck Reactions of Unactivated Alkyl Halides. J. Am. Chem. Soc. 2007, 129, 11340-11341.

(13) (a) Park, Y.; Ahn, S.; Kang, D.; Baik, M. H. Mechanism of RhCatalyzed Oxidative Cyclizations: Closed versus Open Shell Pathways. Acc. Chem. Res. 2016, 49, 1263-1270. (b) Chirik, P. J. CarbonCarbon Bond Formation in a Weak Ligand Field: Leveraging OpenShell First-Row Transition-Metal Catalysts. Angew. Chem., Int. Ed. 2017, 56, 5170-5181.

(14) Wang, G. Z.; Shang, R.; Cheng, W. M.; Fu, Y. IrradiationInduced Heck Reaction of Unactivated Alkyl Halides at Room Temperature. J. Am. Chem. Soc. 2017, 139, 18307-18312.

(15) Kurandina, D.; Rivas, M.; Radzhabov, M.; Gevorgyan, V. Heck Reaction of Electronically Diverse Tertiary Alkyl Halides. Org. Lett. 2018, 20, 357-360.

(16) (a) Zhu, N.; Zhao, J.; Bao, H. Iron catalyzed methylation and ethylation of vinyl arenes. Chem. Sci. 2017, 8, 2081-2085. (b) Ge, L.; Jian, W.; Zhou, H.; Chen, S.; Ye, C.; Yu, F.; Qian, B.; Li, Y.; Bao, H. Iron-Catalyzed Vinylic C-H Alkylation with Alkyl Peroxides. Chem. Asian J. 2018, 13, 2522-2528. (c) Zhou, H.; Ge, L.; Song, J.; Jian, W.; Li, Y.; Li, C.; Bao, H. HOTf-Catalyzed Alkyl-Heck-type Reaction. iScience 2018, 3, 255-263.

(17) (a) Cao, H.; Jiang, H.; Feng, H.; Kwan, J. M. C.; Liu, X.; Wu, J. Photo-induced Decarboxylative Heck-Type Coupling of Unactivated Aliphatic Acids and Terminal Alkenes in the Absence of Sacrificial Hydrogen Acceptors. J. Am. Chem. Soc. 2018, 140, 16360-16367. (b) Wang, G.-Z.; Shang, R.; Fu, Y. Irradiation-Induced PalladiumCatalyzed Decarboxylative Heck Reaction of Aliphatic N-(Acyloxy)phthalimides at Room Temperature. Org. Lett. 2018, 20, 888-891.

(18) Xiong, H.; Ramkumar, N.; Chiou, M.-F.; Jian, W.; Li, Y.; Su, J.H.; Zhang, X.; Bao, H. Iron-Catalyzed Carboazidation of Alkenes and Alkynes. Nat. Commun. 2019, 10, 122.

(19) (a) Quiclet-Sire, B.; Zard, S. Z. Some aspects of radical cascade and relay reactions. Proc. R. Soc. London, Ser. A 2017, 473, 20160859. (b) Robertson, J.; Pillai, J.; Lush, R. K. Radical translocation reactions in synthesis. Chem. Soc. Rev. 2001, 30, 94-103. (c) Xuan, J.; Studer, A. Radical cascade cyclization of 1,n-enynes and diynes for the synthesis of carbocycles and heterocycles. Chem. Soc. Rev. 2017, 46, 4329-4346. (d) Wang, F.; Chen, P.; Liu, G. Copper-Catalyzed Radical Relay for Asymmetric Radical Transformations. Acc. Chem. Res. 2018, 51, 2036-2046.

(20) Bolm, C.; Legros, J.; Le Paih, J.; Zani, L. Iron-catalyzed reactions in organic synthesis. Chem. Rev. 2004, 104, 6217-6254. 